Fall 1996

\title{
Communication Effects on Divorce Mediation: How Participants' Argumentativeness, Verbal Aggression, and Compliance-Gaining Strategy Choice Mediate Outcome Satisfaction
}

Jill E. Rudd

Cleveland State University, J.RUDD@csuohio.edu

Follow this and additional works at: https://engagedscholarship.csuohio.edu/clcom_facpub

Part of the Interpersonal and Small Group Communication Commons

How does access to this work benefit you? Let us know!

\section{Publisher's Statement}

"This is the pre-peer reviewed version of the following article: Rudd, J. E. (1996). Communication effects on divorce mediation: How participants' argumentativeness, verbal aggression, and compliance-gaining strategy choice mediate outcome satisfaction. Mediation Quarterly, 14(1), 65-78. , which has been published in final form at https://doi.org/10.1002/crq.3900140107. This article may be used for non-commercial purposes in accordance with Wiley Terms and Conditions for Use of Self-Archived Versions."

\section{Recommended Citation}

Rudd, Jill E., "Communication Effects on Divorce Mediation: How Participants' Argumentativeness, Verbal Aggression, and Compliance-Gaining Strategy Choice Mediate Outcome Satisfaction" (1996).

Communication Faculty Publications. 62.

https://engagedscholarship.csuohio.edu/clcom_facpub/62

This Article is brought to you for free and open access by the School of Communication at EngagedScholarship@CSU. It has been accepted for inclusion in Communication Faculty Publications by an authorized administrator of EngagedScholarship@CSU. For more information, please contact library.es@csuohio.edu. 


\title{
Communication Effects on Divorce Mediation: How Participants' Argumentativeness, Verbal Aggression, and Compliance-Gaining Strategy Choice Mediate Outcome Satisfaction
}

\author{
Jill E. Rudd
}

Although the use of mediation has been documented to be on the rise, Wall and Dewhurst (1991) point out that "despite interest in the topic of mediation, scholars are still in the early stages of characterizing the behavior of mediators themselves." They argue that much more research is needed to clear up the definitional problems associated with the study of mediation and the conceptual framework within which one ought to frame the process, and they agree with Kressel, Pruitt, and Associates (1989), who argue that "the field of mediation research is still in its very formative stages" (p. 64). The general purpose of this article is to contribute to our growing understanding of the effectiveness of mediation; specifically, as it is used in divorce settlements. Currently communication researchers have focused on the problem-solving communication of the participants and the mediator with little attention given to the effects of the inherently persuasive interactions within mediation. Tedeschi (1972) argued that "Because [mediation] is a process of social construction, negotiation [mediation] involves persuasion" (p. 177). Mediation involves participants' attempts at persuasion in order to reach an agreement. Little is known about the persuasive communicative practices or communicative characteristics of 
individuals who engage in divorce mediation. To examine how the participants' persuasive communicative traits may affect the divorce mediation, this study investigated the relationships among participants' argumentativeness, verbal aggressiveness, and use of compliance-gaining strategies and their level of satisfaction with the divorce mediation process.

\section{Background}

According to Bigoness and Kesner (1986), the most common form of thirdparty dispute intervention is mediation, which is enjoying increasing popularity as a means of settling disputes. Mediators are used to settle disputes within families, between labor and management, and between government agencies and various public groups, and it is increasingly being used in the international arena (Keltner, 1987; Kressel, Pruitt, and Associates, 1989).

I begin by accepting Kressel's definition that divorce mediation is "the process in which divorcing spouses negotiate some or all of the terms of their settlement agreement with the aid of a neutral and trained third party" (1985, p. 179). Sprenkle and Storm (1983) posited that divorce mediation is superior to the traditional adversarial method for resolving child custody issues among couples. It has been estimated that more than 25 percent of all child custody cases that appear before a judge return for future litigation (Mathis and Yingling, 1990). Most of these return cases are reported to be the result of one or both parents' dissatisfaction with the court's original decision. Insofar as mediation generally (and divorce mediation specifically) emphasizes the achievement of mutually satisfying solutions, one can easily argue that if a divorcing couple can reach a mutually satisfying solution regarding the distribution of their resources, not only will court backlogs ease, but couples will feel better about themselves, the divorce process, and their decisions and will be more likely to "live with the outcome."

An integral part of finding a mutually satisfying solution lies in constructive communication. The manner in which couples talk through their issues in mediation is critical to outcome. As this article presents, couples who are able to attack controversial issues without the individuals themselves feeling attacked (referred to in the article as argumentativeness communication) are likely to have a more satisfying outcome. Individuals who attack their partner in order to do some sort of damage to his or her self-concept (referred to as verbal aggressiveness communication) as a way to win the mediation are less likely to find mediation a satisfying process. Furthermore, the specific tactics that participants use to persuade their partner to do something he or she would not have done without persuasion (referred to as compliance-gaining communication) may also add to our understanding of satisfaction with the mediation process.

Scholars have proposed that in resolving divorce disputes mediation is a more satisfying method than the traditional adversarial method in court. 
Several scholars have investigated the disputant's level of satisfaction with the mediation process as a factor in evaluating the effectiveness of mediation (Bohmer and Ray, 1994; Kitzmann and Emery, 1993; Kressel, Frontera, Forlenza, Butler, and Fish, 1994). Wall and Dewhurst (1991) found no differences in satisfaction with either the mediation process or the mediation outcome between groups that either resolved or failed to resolve their differences, with both groups being relatively satisfied. However, it must be pointed out that Wall and Dewhurst looked at satisfaction in the context of small claims courtappointed mediation in which the issues would be significantly less involving than in the case of divorce mediation.

To address the effectiveness of divorce mediation, as measured by satisfaction, White (1985) developed the Satisfaction with Divorce Mediation Instrument (SDMI). The SDMI consists of three subscales: (1) disputants' level of general satisfaction with the mediation process, (2) their satisfaction with mediated property settlement and finance issues, and (3) satisfaction with the mediated outcome of child custody and visitation rights. This instrument has been shown to be reliable and valid (White, 1985). Although several scholars have examined satisfaction, with the exception of Wall and Dewhurst (1991) few have investigated disputants' level of satisfaction and its relationship to other communication factors in the mediation process.

Compliance-Gaining Strategies. Putnam (1988) proposed that future research in negotiation (such as mediation) needs to focus on power and conflict by looking specifically at types of compliance-gaining strategies. The study of compliance-gaining began with Marwell and Schmitt's seminal work in 1967. Wheeless, Barraclough, and Stewart (1983) define compliance-gaining as the "communicative behavior in which an agent engages so to elicit from a target some agent-selected behavior" (p. 111). Further explanation of compliancegaining strategies is that (1) compliance-gaining is person A getting person B to do or comply with A's wishes, where B would not have otherwise done so without A's inducement; (2) compliance is relatively immediate; that is, the attempt to elicit a response and the response itself (compliance or noncompliance) are closely related in time; and (3) power is an essential part of compliance-gaining in that the type of power a person has will determine the choice of compliancegaining strategy. Other studies have examined compliance-gaining behaviors in a variety of situations. Miller, Boster, Roloff, and Seibold (1977) noted that the type of situation (interpersonal or noninterpersonal) is the predominant factor in the selection of compliance-gaining messages.

Miller and Steinberg (1975) argued that the distinction between interpersonal and noninterpersonal communication lay in the data one used to predict the other party's response during interaction. In the noninterpersonal communication situation, participants rely on general cultural or social norms when interacting with each other. In the interpersonal situation, participants rely on their knowledge of the other's psychological make-up and in that context are able to offer explanations as to why the other is responding or acting 
as he or she is. Thus the use of compliance-gaining strategies should vary considerably, based on how well one knows the other participant (see, for example, Cody, McLaughlin, and Jordan, 1980; Falbo, 1977; Johnson, 1976). Insofar as this investigation concerned divorce mediation, one may reasonably conclude that the participants operate at the interpersonal level and consequently should utilize interpersonal compliance-gaining strategies. Given that premise, a typology of interpersonal compliance-gaining strategies was developed and utilized in this study.

A number of interpersonal compliance-gaining strategies were reviewed (Cody, McLaughlin, and Jordan, 1980; Falbo, 1977; Fitzpatrick and Winke, 1979; Johnson, 1976; Miller, Boster, Roloff, and Seibold, 1977; Wiseman and Schenck-Hamlin, 1981). Based on this review, a typology description of the final set of strategies used in this study emerged. The compliance-gaining strategies listed below are divided into prosocial and antisocial strategies as determined by previous studies.

\section{Prosocial}

1. Ingratiation. One party precedes request for compliance with offer of goods, sentiments, services, favors, positive reinforcement, or supportive listening. Ingratiation can range from subtle verbal or nonverbal positive reinforcement to more blatant forms of "apple polishing" or "brown-nosing" (Johnson, 1976; Wiseman and Schenck-Hamlin, 1981).

2. Promises. A party promises goods, sentiments, services, favors, in exchange for compliance. A variation of the promise is compromise, in which gains and losses are perceived in relative terms so that both source and receiver give in order to receive what they want from each other (Cody, McLaughlin, and Jordan, 1980; Marwell and Schmitt, 1967; Wiseman and Schenck-Hamlin, 1981).

3. Esteem. One party persuades the other that compliance will result in an increase in other's power, success, status, moral or ethical standing, attention and affection of others, competence, ability to handle failure and uncertainty well, or attempts to aspire (Fitzpatrick and Winke, 1979; Marwell and Schmitt, 1967; Wiseman and Schenck-Hamlin, 1981).

4. Allurement. The source of a reward arises from other than the disputants. Compliance could result in a circumstance in which other people become satisfied, pleased, or happy (Wiseman and Schenck-Hamlin, 1981).

5. Altruism. One party requests the other to engage in behavior designed to benefit that party. Presentation of some personal need and asking for help are typical. The appeal may be manipulated by making other feel unselfish, generous, self-sacrificing, heroic, or helpful. "It would help me if you would do this" and "Do a favor for me" exemplify the direct approach of the altruistic strategy. Two variants are sympathy ("I am in big trouble, so help me") and empathy ("You would ask for help if you were me") (Cody and McLaughlin, 1980; Marwell and Schmitt, 1967; Wiseman and Schenck-Hamlin, 1981). 
6. Direct Request. Party simply asks the other to comply. Motivation or inducement for complying is not provided, but must be inferred by the receiver. The party's message appears to offer as little influence as possible, so the other is given the maximum latitude of choice. "If I were you, I would ..." and "Why don't you think about ..." are instances of direct requests (Falbo, 1977; Wiseman and Schenck-Hamlin, 1981).

7. Explanation. Reasons are advanced for gaining compliance from other. Reasons may include credibility ("I know from experience") or inference from empirical evidence ("Everything points to the logic of this step") (Cody, McLaughlin, and Jordan, 1980; Falbo, 1977; Johnson, 1976; Wiseman and Schenck-Hamlin, 1981).

8. Empathetic. One party engages the other in talk that allows them to disagree without arguing, for example, discussing the possibilities of accepting each other's point of view (Fitzpatrick and Winke, 1979).

\section{Antisocial}

9. Debt. One party recalls obligations owed him or her as a way of inducing the receiver to comply. Debts may be as tangible as favors or loans or as general as the catch-all ("After all I've done for you") statement (Fitzpatrick and Winke, 1979; Marwell and Schmitt, 1967; Wiseman and Schenck-Hamlin, 1981).

10. Aversive Stimulation. One party continuously punishes the other, making cessation contingent on compliance. Pouting, sulking, crying, acting angry, whining, "the silent treatment," and ridicule are examples of aversive stimulation (Marwell and Schmitt, 1967; Fitzpatrick and Winke, 1979).

11. Threat. A party's proposed actions will have negative consequences for the receiver if he or she does not comply. Black-mailing, the suggestion of firing, violence, or breaking off a friendship would all be examples of threats (Cody, McLaughlin, and Jordan, 1980; Falbo, 1977; Marwell and Schmitt, 1967; Wiseman and Schenck-Hamlin, 1981).

12. Guilt. Failure to comply will result in decrease of self-worth. Areas of inadequacy might include professional ineptness, social irresponsibility, or ethical or moral transgressions (Wiseman and Schenck-Hamlin, 1981).

13. Warning. Punishment arises from sources other than the disputants. Noncompliance could lead to a circumstance in which other people become embarrassed, offended, or hurt, resulting in negative attitudes from those people. "You'll make the boss unhappy" and "What will the neighbors say?" are examples (Wiseman and Schenck-Hamlin, 1981).

14. Hint. One party presents the situational context in such a way that the receiver is led to conclude the desired action or response. These are usually "indirect" requests like "It sure is hot in here" that imply a response like "Open the window" (Falbo, 1977; Wiseman and Schenck-Hamlin, 1981).

15. Deceit. One party gains the other's compliance by intentionally misrepresenting the characteristics or consequences of the desired response. For 
example, saying "It's easy" when in fact it isn't, or offering a reward that party can't deliver (Cody, McLaughlin, and Jordan, 1980; Falbo, 1977; Johnson, 1976; Wiseman and Schenck-Hamlin, 1981).

16. Bargaining. Parties explicitly offer to trade favors in exchange for other desired goals (Falbo, 1977).

17. Other. Strategies that respondents were unable to categorize.

One would presume that the party's or the other's use of prosocial compliance-gaining strategies would result in greater satisfaction with divorce mediation. It is not clear how the use of antisocial compliance-gaining strategies would affect satisfaction. In bitterly contested divorces the use of an antisocial strategy might be more satisfying for the party using it but less satisfying for the recipient (other). On the other hand, these relationships could be just the opposite. For example, a party might be more satisfied seeing the former spouse using antisocial strategies if that was seen as indicative of frustration and there was a desire on the part of party to inflict emotional harm on the spouse during the-mediation process. Thus one might have some expectations regarding prosocial strategies, but the question of antisocial strategies is left open.

Argumentativeness. Argumentativeness is "a generally stable trait which predisposes the individual in communicative situations to advocate positions on controversial issues and to attack verbally the positions which other people take on these issues" (Infante and Rancer, 1982, p. 72). Those individuals skilled in argumentation tend to be interested in discussion, are less likely to be aroused by verbal aggression, and appear more flexible in nature. Rancer, Baukus, and Infante (1985) found that highly argumentative people are likely to perceive arguing to be an invigorating and satisfying experience, whereas less argumentative people are likely to perceive arguing as an unpleasant, destructive experience. Hunter and Boster (1987) argued that individuals high in argumentativeness tend to avoid using communication messages that may inflict psychological damage to their opponent.

Thus argumentativeness, as a psychological trait, may be central to explaining two specific characteristics of mediation. First, argumentativeness may help explain satisfaction with the mediation process, inasmuch as those who score high in argumentativeness should enjoy mediation more than those who do not (the presentation of arguments being inherent in mediation). Second, while not specifically tested in this study, argumentativeness should also be related to whether an agreement is reached. One would expect those who are (1) more comfortable with disagreement, (2) more concerned about the other's point of view, and (3) less likely to use compliance-gaining strategies that hurt their opponent to be more satisfied with the mediation process and more likely to arrive at a solution.

Verbal Aggressiveness. Verbal aggression is a distinct form of communication behavior characterized by damaging self-concepts, embarrassment, frustration, anxiety, anger, and damaged relationships (Infante, Trebing, Shepherd, 
and Seeds, 1984). Verbal aggressiveness is characterized by attacks against the self-concepts of people in order to deliver psychological pain (Infante and Wigley, 1986). Early work on the relationship between verbal aggressiveness and argumentativeness found the variables to be unrelated. Individuals who are more verbally aggressive and less argumentative are more likely to resort to physical violence in marital relationships than those who were less verbally aggressive (Infante, Chandler, and Rudd, 1989). Thus individuals who use more verbally aggressive messages in attempt to persuade their partner may find mediation a frustrating process.

Individuals classified as verbally aggressive may well perceive divorce mediation as an opportunity to vent frustration with their spouses. However, verbal aggression is generally prohibited by the presence of the mediator. Furthermore, they may feel limited in their choice of acceptable strategies, specifically antisocial strategies. Thus the verbally aggressive individual ought to find mediation generally unsatisfactory.

In the study presented here, I propose to shed some light on the interrelatedness of compliance-gaining strategies (both pro- and antisocial), argumentativeness, verbal aggressiveness, and satisfaction with divorce mediation. I examine these relationships in terms of self and self's perception of other (the spouse). Given the exploratory nature of this work, I frame the focus in terms of "expectations" rather than questions or hypotheses. On the basis of the preceding discussion, I expect the following relations to hold:

1. The use of prosocial compliance-gaining strategies by both self and spouse is expected to be positively related to satisfaction with the mediation process.

2. The perceived use of antisocial compliance-gaining strategies by the spouse is expected to be negatively related to satisfaction.

3. Argumentativeness is expected to be positively related to satisfaction with the mediation process.

4. Spouse's perceived argumentativeness is expected to be positively related to satisfaction with the mediation process.

5. Verbal aggressiveness is expected to be negatively related to satisfaction with the mediation process.

6. Spouse's perceived verbal aggressiveness is expected to be negatively related to satisfaction with the mediation process.

\section{Method}

Sample. This study is based on interviews of eighty-seven couples who participated in court-related divorce mediation, specifically to settle child custody and visitation issues. The sample was drawn from mediation sessions associated with mediation centers and court-related programs in Ohio, Florida, and Indiana. The sample was limited to mediations that were new in the sense 
that the issues being mediated were not a continuation of old problems. It was also limited to mediation that lasted no more than five sessions. Each session lasted approximately one hour and took, on average, 1.5 sessions to resolve. The couples had been married for an average of 8.6 years, had lived apart for 16.9 months, and had an average of 2.2 children. Seventy-five percent of those who reported race were Caucasian, had completed at least high school (98.7 percent), and had a family income over $\$ 10,000$.

Procedure. A brief explanation of this research was given to the participants prior to their mediation sessions. Each participant was told the purpose of the study (to examine the type of communication couples use during divorce mediation); the attorneys were also informed of the nature of this study and the use of the data; and each participant was asked to sign a consent form and complete a questionnaire before leaving the mediation setting. Data were collected from each pair of disputants immediately following the final mediation session.

The questionnaire asked participants to recall the compliance-gaining strategies they and their spouses had used as well as their frequency of use. The questionnaire also elicited their own, and their spouse's, argumentativeness and verbal aggressiveness. Finally, individuals rated their satisfaction with the process. The demographics of the couples were also collected (Table 1). Thus the questionnaire consisted of a number of instruments, the specifics of which are detailed below.

Compliance-Gaining Strategies. The factor analysis produced a two-factor structure similar to that discovered by Roloff and Barnicott (1978). Factor 1, named antisocial strategies, is composed of allurement, deceit, warning, threat, esteem debt, altruism, guilt, and direct request. Factor 1 (antisocial strategies) accounted for 32.7 percent of the variance (Eigenvalue $=3.90$, see Table 2). Factor 1 was then tested for reliability. The alpha coefficient was .84 .

Ingratiation, promise, and explanation loaded on Factor 2, which seemed to represent prosocial strategies. Factor 2 explained 16.6 percent of the variance (Eigenvalue $=2.03$ ). These items were then tested for reliability. The alpha coefficient was .66. Hinting, adverse stimulation, bargaining, and empathy failed to meet the factor criteria described above, therefore these strategies were dropped. ${ }^{1}$

Argumentativeness. The ten-item short version of Infante and Rancer's (1982) Argumentativeness Scale was used to measure argumentativeness in the divorce mediation context. The original twenty-item scale was composed of trait-type items that measure approaching argumentativeness (ARGap) and avoiding argumentativeness (ARGav). The ARGap factor yielded a reliability coefficient of .91, and the ARGav factor yielded a coefficient of .86 (Infante and Rancer, 1982). The present study used the ten-item short version of this scale, which has been used in previous studies (Infante and Gorden, 1985; Infante, Chandler, and Rudd, 1989).

Past researchers have reported reliabilities in the .80's (Rancer, Baukus, and Infante, 1985). However, when the traitlike items were reworded to reflect 
Table 1. Demographic Frequencies and Percentages

\begin{tabular}{lrr}
\hline Variable & $\begin{array}{c}\text { Response } \\
\text { Frequency }\end{array}$ & Percentage \\
\hline Ethnic/Racial Background & & \\
White & 108 & 75.0 \\
Black & 20 & 13.9 \\
Hispanic & 10 & 6.9 \\
Asian & 2 & 1.4 \\
Other & 4 & 2.8 \\
Completed Education & & \\
Grade school & 2 & 1.4 \\
High school & 40 & 27.8 \\
Technical school & 24 & 16.7 \\
Some college & 30 & 20.8 \\
College & 32 & 22.2 \\
Some graduate school & 8 & 5.6 \\
Graduate school & 8 & 5.6 \\
Family Income & & \\
\$10,000-19,999 & 20 & 14.3 \\
$\$ 20,000-29,999$ & 38 & 27.1 \\
$\$ 30,000-39,999$ & 22 & 15.7 \\
$\$ 40,000-49,999$ & 32 & 22.9 \\
$\$ 50,000$ or more & 28 & 20.0 \\
\hline
\end{tabular}

Note: No responses: Ethnic $=30 ;$ Education $=30 ;$ Income $=34$

Table 2. Compliance-Gaining Principal Component Factor Analysis with Varimax Rotation

\begin{tabular}{|c|c|c|c|}
\hline Strategy & $\begin{array}{c}\text { Antisocial Strategies } \\
\text { (Factor 1) }\end{array}$ & $\begin{array}{c}\text { Prosocial Strategies } \\
\text { (Factor 2) }\end{array}$ & Communality \\
\hline Allurement & .70 & .02 & .49 \\
\hline Deceit & .73 & -.25 & .60 \\
\hline Warning & .65 & .12 & .44 \\
\hline Threat & .70 & -.16 & .52 \\
\hline Esteem & .64 & .05 & .40 \\
\hline Debt & .68 & .14 & .49 \\
\hline Altruism & .57 & .05 & .32 \\
\hline Guilt & .64 & .08 & .42 \\
\hline Direct request & .59 & .27 & .42 \\
\hline Ingratiation & .03 & .85 & .72 \\
\hline Promise & .08 & .81 & .65 \\
\hline Explanation & .01 & .67 & .45 \\
\hline Eigenvalues & 3.92 & 1.99 & \\
\hline Variance explained & $32.7 \%$ & $16.6 \%$ & \\
\hline \multicolumn{4}{|c|}{ Total variance explained: $49.3 \%$} \\
\hline
\end{tabular}


arguing with one's spouse, the alpha was in the .70's (Infante, Chandler, and Rudd, 1989). The alpha in this study for the self-report of argumentativeness was .67 and for the report of spouse argumentativeness .75, with a mean of 31.64 and a standard deviation of 6.65 .

Verbal Aggressiveness. A ten-item short version of the Verbal Aggressiveness Scale (Infante and Wigley, 1986) was adapted to measure verbal aggressiveness in the divorce mediation context. These trait items were reworded to reflect the communication with one's spouse. The original twentyitem Verbal Aggressiveness Scale has been found to be consistently unidimensional and to have an alpha of .81 (Infante and Wigley, 1986). Previous researchers reported the ten-item short version to have reliabilities in the high .70 's and 80's (Infante and Gorden, 1985; Infante, Chandler, and Rudd, 1989). The coefficient alpha for this study was .67 for ratings of self verbal aggressiveness with a mean of 28.44 and a standard deviation of 5.95 , and .79 for ratings of spouse verbal aggressiveness with a mean of 33.34 and a standard deviation of 6.96 .

Satisfaction with Divorce Mediation Instrument. White's (1985) twentynine-item Satisfaction with Divorce Mediation Instrument was modified to a fourteen-item scale to fit the child custody and visitation mediation context of the present study. Twelve of the items are from White's subscale of child custody and visitation, and two items are from the general subscale. The items were summed to determine the satisfaction score. The reliability coefficient was .92 with a mean of 48.12 and a standard deviation of 9.01 .

\section{Results}

Table 3 presents a stepwise regression analysis with satisfaction as the dependent variable. Report of spouse's verbal aggressiveness was entered on the first step and had a beta of -.26 ; report of spouse's use of antisocial strategies was entered second and had a beta of -.19; self-report use of prosocial strategies use was the third entry with a beta of .22; self-report of argumentativeness was entered fourth and had a beta of .25; and finally, self-report of verbal aggressiveness was entered with a beta of -.17 . Self-report of antisocial compliancegaining strategies use, report of spouse's use of prosocial and antisocial strategies, and report of spouse's argumentativeness failed to meet the criteria for entry but were in the same direction of their counterparts discussed above.

\section{Discussion}

A stepwise regression analysis was conducted to determine the relationship of compliance-gaining strategies, argumentativeness, and verbal aggressiveness with satisfaction with the mediation. These findings suggest that the more participants used prosocial compliance-gaining strategies the more satisfied they were with the mediation. ${ }^{2}$ This is in agreement with past research, which has 
Table 3. Stepwise Multiple Regression Analysis of Satisfaction with Divorce Mediation on Verbal Aggression, Argumentativeness, and Compliance-Gaining

\begin{tabular}{lcccc}
\hline Predictors & Step & $R$ & $R^{2}$ & Beta \\
\hline Report of spouse's verbal aggressiveness & 1 & .26 & .07 & $-.26^{*}$ \\
Report of spouse's use of antisocial strategies & 2 & .32 & .10 & $-.19^{*}$ \\
Self-report of prosocial strategies & 3 & .39 & .15 & $.22^{*}$ \\
Self-report of argumentativeness & 4 & .42 & .18 & $.25^{*}$ \\
Self-report of verbal aggressiveness & 5 & .45 & .20 & $-.17^{*}$ \\
\hline
\end{tabular}

$R=.45 ; R^{2}=.20 ; F=8.70 ; p<.01$, df $5 / 173$

" $p<.05 ; " p<.01$

proposed that cooperation and the collaboration of the participants are critical to successful negotiations (Donohue, Allen, and Burrell, 1985). What this finding provides for divorce mediators is that an important part of the mediation process is promoting the use of prosocial strategies to participants. The implication for future conflicts the couples may have is that using prosocial strategies to persuade an ex-spouse may not only be beneficial but also satisfying.

The findings also suggest that individuals who reported using more verbally aggressive messages were less satisfied with the mediation. These results are consistent with previous research that found verbal aggressiveness had negative effects in other contexts, such as organizations and families (Infante and Gorden, 1985; Infante, Chandler, and Rudd, 1989). An explanation for this may lie in the structure of the mediation process, which deters participants from using any personal attacks or insults. Since mediators are trained to intervene in the mediation process, it is not surprising that individuals who reported using more verbally aggressive messages found it frustrating and unsatisfying to be in an environment that restrained their preferred method of communicating. What this also suggests to the mediator is that in order to provide a more satisfying mediation for the more verbally aggressive communicators, the mediator may need to teach such individuals more-productive communication skills. Individuals who are more verbally aggressive may not find the mediation process conducive to their communication style; they may chose a more adversarial method, as in the court, for resolving their disputes. These findings are consistent with Blades's (1984) work, which suggested that overbearing or aggressive individuals are not appropriate candidates for mediation.

Participants who are more argumentative found the mediation process satisfying. This finding may also be a result of the mediation structure. The mediation process encourages participants to talk to each other and find ways of resolving their dispute, with the intervention of a third party when necessary. Individuals who are higher in the argumentative trait enjoy debating issues and believe they have the ability to do well in arguments (Infante and Rancer, 
1982). Mediation is a process that allows participants to engage in debating controversial issues in hopes of reaching a workable solution. The relationship of argumentativeness and satisfaction, therefore, is supportive of theory regarding the argumentative individual.

The report of spouse's use of antisocial compliance-gaining strategies was also found to be significantly related to satisfaction with the mediation. These results suggest that when individuals perceive their spouse as using antisocial compliance-gaining strategies, they are less satisfied with the mediation process.

In summary, these findings suggest that the more argumentative individuals who are more verbally aggressive may not be well served by the mediation process in that they find it less satisfying, which may ultimately return them to the judicial system for further litigation. The findings of this study also offer some insight into which type of compliance-gaining strategies result in higher levels of participants' satisfaction. Divorce mediators should promote participants' use of prosocial strategies, which will likely create a more satisfying agreement. Furthermore, mediators' early identification and intervention of participants' use of antisocial compliance-gaining strategies may prevent a course of dissatisfaction with the divorce mediation agreement. If the mediator is able to encourage prosocial strategies and prevent the use of antisocial strategies, the result is likely to be a mutually satisfying divorce agreement.

\section{Notes}

1. There has been considerable amount of research studying the underlying factors of compliance-gaining strategies (Marwell and Schmitt, 1967; Miller, Boster, Roloff, and Seibold, 1977; Roloff and Barnicott, 1978). Therefore a factor analysis using a principal components extraction with an orthogonal (varimax) rotation was conducted. Factor stability was based on the following criteria: factors must have an Eigenvalue greater than 1; items must have a loading of at least .50 on one factor and no larger than .30 on a second factor; and at least three items had to load on each factor (Hair, Anderson, and Tatham, 1987).

2. A two-factor solution emerged similar to Roloff and Barnicott's (1978) factor structure. The first factor, named antisocial strategies, was composed of allurement, deceit, warning, threat, esteem, debt, altruism, guilt, and direct request. In reviewing previous research, I did not expect allurement, esteem, altruism, and direct request to load on the antisocial strategies factor. However, given the conflictual context in which these compliance-gaining strategies were used, these strategies have an antisocial connotation. Allurement was defined as "I explained how agreeing would make other people respect him or what he was doing." In the divorce mediation context, where frustration with the other participant is high, a spouse may have interpreted allurement as an inappropriate strategy for his or her former spouse to be using. Often the feelings the couple expressed were feelings of disrespect for their partner's opinion or anyone else's that their partner mentioned. The general overtone of the conversation might be characterized as a feeling of "I don't care what you or anyone else think." In more productive relationships couples often care about others' opinions and desire their respect, which would explain why previous research found allurement to be a more positive or prosocial strategy and why this study found it to be an antisocial strategy. Esteem was conceptualized in this study as "I told him how good he would feel if he would agree with me or I suggested it was the right thing to do." This strategy is to appeal to the individual increase in self-worth. However, in the divorce mediation context, participants may have perceived this as an attack on their character. In a relationship that is deteri- 
orating, a suggestion that your partner knows what will make you feel better about yourself may be viewed as an attack on the individual's current self-worth. Thus this strategy is viewed as inappropriate for divorcing partners to use and loads on the antisocial strategies factor. Altruism was defined as a strategy in which the source requests the receiver to engage in behavior designed to benefit the source rather than the receiver but makes the receiver feel unselfish, generous, or selfsacrificing for helping the source. In ongoing relationships, individuals would usually feel positive or good about helping another person. However, in the divorce mediation setting, individuals are fighting for their wants and no longer have a high regard for their partner's wishes. Therefore, participants involved in the mediation viewed appealing to their partner's unselfishness or appearing helpless as an inappropriate or antisocial strategy. Direct request was conceptualized in this study as "I asked him to simply agree with my suggestion or solution." In a conflictual situation such as divorce mediation, this strategy may be seen as a demand and thus becomes associated with antisocial strategies.

\section{References}

Bigoness, W. J., and Kesner, I. F. "Mediation Effectiveness: What Can We Learn from Leadership Research?" In R. J. Lewicki, B. H. Sheppard, and M. H. Bazerman (eds.), Research on Negotiations in Organizations. Vol. 1. Greenwich, Conn.: JAl Press, 1986.

Blades, J. "Mediation: An Old Art Revitalized." Mediation Quarterly, 1984, 3, 59-96.

Bohmer, C., and Ray, M. L. "Effects of Different Dispute Resolution Methods on Women and Children After Divorce." Family Law Quarterly, 1994, 28, 223-245.

Boster, F. J. "Argumentation, Interpersonal Communication, Persuasion, and the Process(es) of Compliance-Gaining Message Use." In J. R. Cox, M. O. Sillars, and G. B. Walkers (eds.), Argument and Social Practice: Proceedings of the Fourth SCA/AFA Conference on Argumentation. Annandale, Va.: Speech Communication Association, 1985.

Cody, M. J., and McLaughlin, M. L. "Perceptions of Compliance-Gaining Situations: A Dimensional Analysis." Communication Monographs, 1980, 47, 132-148.

Cody, M. J., McLaughlin, M. L., and Jordan, W. J. "A Multidimensional Scaling of Three Sets of Compliance-Gaining Strategies." Communication Quarterly, 1980, 28, 34-46.

Donohue, W. A. "An Empirical Framework for Examining Negotiation Processes and Outcomes. Communication Monographs, 1978, 45, 247-257.

Donohue, W. A. "Analyzing Negotiation Tactics: Development of a Negotiation Interact System." Human Communication Research, 1981, 7, 273-287.

Donohue, W. A., Allen, M., and Burrell, N. "Communication Strategies in Mediation." Mediation Quarterly, 1985, 10, 75-89.

Falbo, T. "Multidimensional Scaling of Power Strategies." Journal of Personality and Social Psychology, 1977, 35, 537-547.

Fitzpatrick, M. A., and Winke, J. "You Always Hurt the One You Love: Strategies and Tactics in Interpersonal Conflict." Communication Quarterly, 1979, 27, 3-11.

Hair, J. F., Anderson, R. E., and Tatham, R. L. Multivariate Data Analysis. (2nd ed.) New York: Macmillan, 1987.

Hunter, J. E., and Boster, F. J. "A Model of Compliance-Gaining Message Selection." Communication Monographs, 1987, 54, 63-84.

Infante, D. A. "Aggressiveness." In J. C. McCroskey and J. A. Daly (eds.), Personality and Interpersonal Communication. Thousand Oaks, Calif: Sage, 1987.

Infante, D. A., Chandler, T. A., and Rudd, J. E. "Test of an Argumentative Skill Deficiency Model of Interspousal Violence." Communication Monographs, 1989, 56, 163-175.

Infante, D. A., and Gorden, W. I. "Superiors' Argumentativeness and Verbal Aggressiveness as Predictors of Subordinates' Satisfaction." Human Communication Research, 1985, 12, 117-125.

Infante, D. A., and Rancer, A. S. "A Conceptualization and Measure of Argumentativeness." Journal of Personality Assessment, 1982, 46, 72-80. 
Infante, D. A., Trebing, J. D., Shepherd, P. E., and Seeds, D. E. "The Relationship of Argumentativeness to Verbal Aggression." Southern Speech Communication Journal, 1984, 50, 67-77.

Infante, D. A., and Wigley, C. J. "Verbal Aggressiveness: An Interpersonal Model and Measure." Communication Monographs, 1986, 53, 61-69.

Johnson, P. "Women and Power: Toward a Theory of Effectiveness. Journal of Social Issues, 1976, 32, 99-109.

Keltner, J. "Mediation." Paper presented at the annual meeting of the Speech Communication Association, Virginia, 1987.

Kitzmann, K. M., and Emery, R. E. "Procedural Justice and Parents' Satisfaction in a Field Study of Child Custody Dispute Resolution." Law and Human Behavior, 1993, 17, 553-567.

Kressel, K. The Process of Divorce. New York: Basic Books, 1985.

Kressel, K., Frontera, E. A., Forlenza, S., Butler, F., and Fish, L. "The Settlement-Orientation vs. the Problem-Solving Style in Custody Mediation." Journal of Social Issues, 1994, 1, 67-84.

Kressel, K., Pruitt, D. G., and Associates. Mediation Research. San Francisco: Jossey-Bass, 1989.

Marwell, G., and Schmitt, D. R. "Dimensions of Compliance-Gaining Behavior: An Empirical Analysis." Sociometry, 1967, 30, 350-364.

Mathis, R. D., and Yingling, L. C. "Family Functioning Level and Divorce Mediation Outcome." Mediation Quarterly, 1990, 8, (1), 3-12.

Miller, G., Boster, F., Roloff, M., and Seibold, D. "Compliance-Gaining Message Strategies: A Typology and Some Findings Concerning Effects of Situational Differences." Communication Monographs, 1977, 44, 37-51.

Miller, G., and Steinberg, M. Between People: A New Analysis of Interpersonal Communication. Chicago: Science Research Associates, 1975.

Putnam, L. L. "Conflict in Group Decision-Making." In R. Hirokawa and M. S. Poole (eds.), Communication and Group Decision-Making. Thousand Oaks, Calif.: Sage, 1988.

Putnam, L. L., and Jones, T. S. "The Role of Communication in Bargaining." Human Communication Research, 1982, 8, 262-280.

Rancer, A. J., Baukus, R. A., and Infante, D. A. "Relations Between Argumentativeness and Belief Structures About Arguing." Communication Education, 1985, 34, 7-47.

Rancer, A. S., and Infante, D. A. "Relations Between Motivation to Argue and the Argumentativeness of Adversaries." Communication Quarterly, 1985, 33, 209-218.

Roloff, M. E., and Barnicott, E. F. "The Influence of Dogmatism on the Situational Rise of Proand Anti-social Compliance-Gaining Strategies." Southern Speech Communication Joumal, 1978, 45, 37-54.

Sprenkle, D. H., and Storm, C. L. "Divorce Therapy Outcome Research: A Substantial and Methodological Review." Journal of Marital and Family Therapy, 1983, 9, 239-258.

Tedeschi, J. T. The Social Influence Processes. Chicago: Aldine \& Atherton, 1972.

Wall, V., and Dewhurst, M. "Mediator Gender: Communication Differences in Resolved and Unresolved Mediation." Mediation Quarterly, 1991, 9, 63-85.

Wheeless, L., Barraclough, R., and Stewart, R. "Compliance-Gaining and Power in Persuasion." In R. N. Nostrom (ed.), Communication Yearbook. Vol. 7. Thousand Oaks, Calif.: Sage, 1983.

White, J. "Developing an Instrument to Measure Satisfaction with Divorce Mediation." Mediation Quarterly, 1985, 10, 91-97.

Wiseman, R. L., and Schenck-Hamlin, W. "A Multidimensional Scaling Validation of an Inductively-Derived Set of Compliance-Gaining Strategies." Communication Monographs, 1981, 48, 252-270.

Jill E. Rudd is assistant professor of communication at Cleveland State University. 
Copyright of Mediation Quarterly is the property of Jossey-Bass Publishers and its content may not be copied or emailed to multiple sites or posted to a listserv without the copyright holder's express written permission. However, users may print, download, or email articles for individual use. 